\title{
Influence of oxygen flow rate on the characteristics of the Tungsten Oxide using RF Magnetron Sputtering
}

\author{
S.A.Abdullah, N.Nafarizal, M.Z.Sahdan \\ Faculty of Electrical and Electronic Engineering, \\ Universiti Tun Hussein Onn Malaysia \\ Batu Pahat, Johor \\ he120081@siswa.uthm.edu.my, nafa@uthm.edu.my, zainizan@uthm.edu.my
}

Keywords-Tungsten Oxide (WO3); RF sputtering, sputtering oxygen

\begin{abstract}
Tungsten Oxide (WO3) thin films were deposited using 99.9\% pure tungsten target onto ITO substrate using RF magnetron sputtering in the range oxygen flow rates of 30-50\%. The influence of the oxygen flow rate on characteristic of WO3 thin films has been investigated. The transmittance, resistivity, crystallite, roughness, and surface morphology were measured by UVVis, 2-point probe, X-Ray Diffraction (XRD), Atomic Force Microscopy (AFM), and Field Emission Scanning Electron Microscopy (FE-SEM) respectively. Experimental result showed that the deposition rate of WO3 thin films decreased by increasing oxygen flow rate. A poor crystalinity or more too amorphous of WO3 thin films produces by using various oxygen content. A higher optical transmittance spectrum detected at $30 \%$ oxygen content about $86 \%$ at wavelength $550 \mathrm{~nm}$.
\end{abstract}

\section{INTRODUCTION}

WO3 have been studied due to their characteristic on optical transmittance since 1980s with the realization WO3 acting as electrochromic materials. The most promising WO3 widely used in smart glass, gas sensor, automotive rear-view mirrors, and sun roofs [1]. WO3 shows a strong ion intercalation behavior which is this ion insertion is combined with a strong change of the oxide and this effect is exploited intensively in electrochromic (EC) device [2]. Several method for prepared a WO3 have been studied by researcher include vacuum evaporation, pulse laser deposition, magnetron sputtering, spray pyrolysis, chemical vapor deposition (CVD), electrodeposition and solgel deposition [3]. RF and DC Magnetron Sputtering process widely used due to better adhesion on the substrate and Sputter deposited films have a composition close to source material. Since the electrical properties, optical properties and microstructure of the sample is depend on the sputtering condition, thus it is important to control sputtering parameter to obtain a good WO3 thin film for EC materials. In this study we examine influence of oxygen flow on WO3 thin film using 30-50\% oxygen flow by using flow ratio of $\mathrm{O} 2 /(\mathrm{Ar}+\mathrm{O} 2)$.

\section{EXPERIMENTAL PROSEDURE}

\section{A. Sample preparation}

WO3 thin films were prepared by RF magnetron reactive sputtering using 3-in diameter tungsten target with $99.9 \%$ purity by changing oxygen content parameter. The substrate used to receive deposited ion is Indium-tin-oxide (ITO) with sheet resistance $20-80 \Omega / \mathrm{cm}^{2}$. The area of sample was fixed to $2.5 \mathrm{~cm} \times 2.5 \mathrm{~cm}$, it cleaned using ultrasonic in acetone and ethanol, and dried in flowing nitrogen gas. The target was sputtered for $10 \mathrm{~min}$ before fabrication process to clean the target surface from any oxide layer. The fabrication process was conducted in argon and oxygen atmosphere with base pressure of $1 \times 10^{-6}$ Torr and working pressure of $5 \times 10^{-3}$ Torr. The RF sputtering power is $100 \mathrm{~W}$ and duration for fabrication is $40 \mathrm{~min}$ with distance target to substrate about $14 \mathrm{~cm}$.

\section{B. Characterization}

The crystal structure WO3 thin films were studied by X-ray diffraction (XRD). Fe-sem and AFM was performed to measure the crystallite and surface morphology of samples. The optical measurement was performed in the wavelength region of $300 \mathrm{~nm}$ to $800 \mathrm{~nm}$ with a UV-Vis spectrometer. Analysis for deposition rate was conducted by using surface profiler machine. 


\section{RESULT AND DISCUSSION}

Fig. 1 show the deposition rate for WO3 thin films deposited into ITO substrate using various oxygen flow. The deposition rate of films decreased by increasing oxygen flow rate in the sputtering chamber, at $30 \%$ oxygen content WO3 film show highest deposition rate at $1.736 \mathrm{~nm} / \mathrm{min}$. Besides, higher oxygen content causes smaller incident energy of Ar ions on target in magnetron sputtering chamber, thus produce a gradually decrease of deposition rate [4].

Fig. 2 illustrates the abilities of current to flow on WO3 thin film based on resistivity of films. The electrical resistivity of oxide films was calculated from resistance using I-V characteristic machine. Resistivity increased by increasing oxygen flow rate during fabrication process. At oxygen flow rate $50 \%$, the resistivity shows higher value $3.02 \mathrm{~m} . \Omega$.

\section{A. Structure and composition}

The XRD pattern of WO3 thin films was shown in Fig.3. A low diffraction peak shown in the XRD pattern, the film pattern consist of broad hump without discernable WO3 diffraction peak and indicating that the film is poor crystalline, except for diffraction peak of ITO substrate. It indicated that the film is in amorphous state or mixed amorphous and nanocrystalline in nature. The amorphous diffraction pattern may cause by amorphous property and internal stress of WO3 films [4].

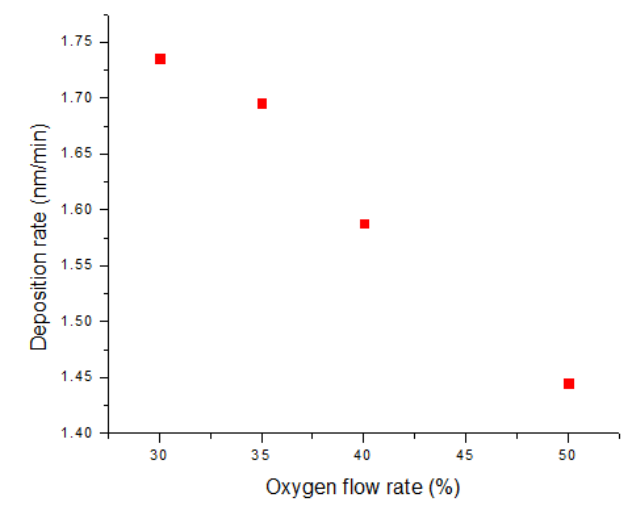

Fig.1. Deposition rate of $\mathrm{WO}_{3}$ thin films deposited at different oxygen content.

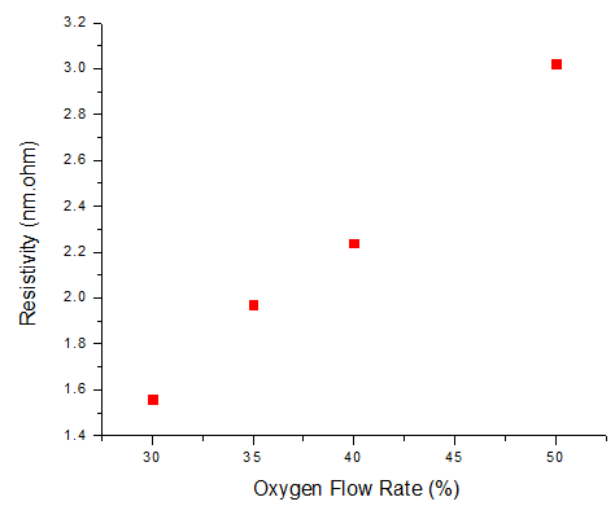

Fig.2. Resistivity change of $\mathrm{WO}_{3}$ thin films deposited at different oxygen content.

The surface morphological features of WO3 thin films are presented in Fig.4. The WO3 thin film has some big particles distributed randomly on surface, however generally the surface is flat and smooth and this shape clarify that the films is in amorphous state. Besides, Sample fabricated on $45 \%$ oxygen flow shows a small distance between particles. These particles consist of formation of tungsten and oxygen which means this sample has small crystalline structure but more too amorphous $[5,6]$. 


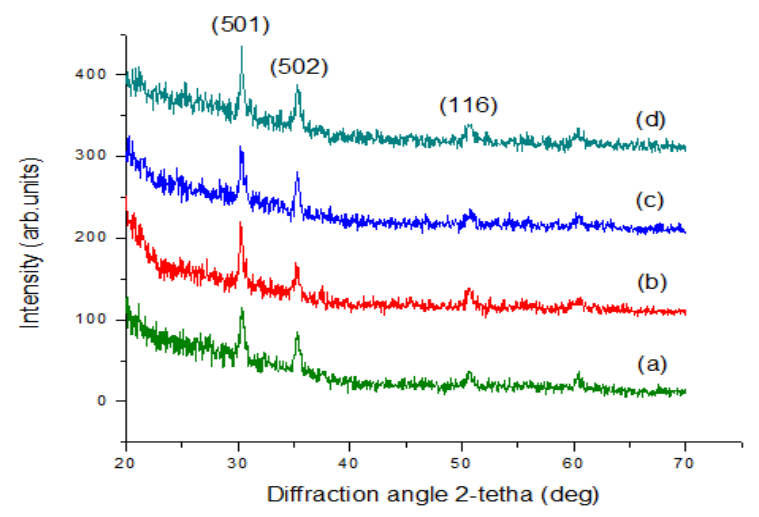

Fig.3. X-ray diffraction pattern of $\mathrm{WO}_{3}$ films prepared at different oxygen content.

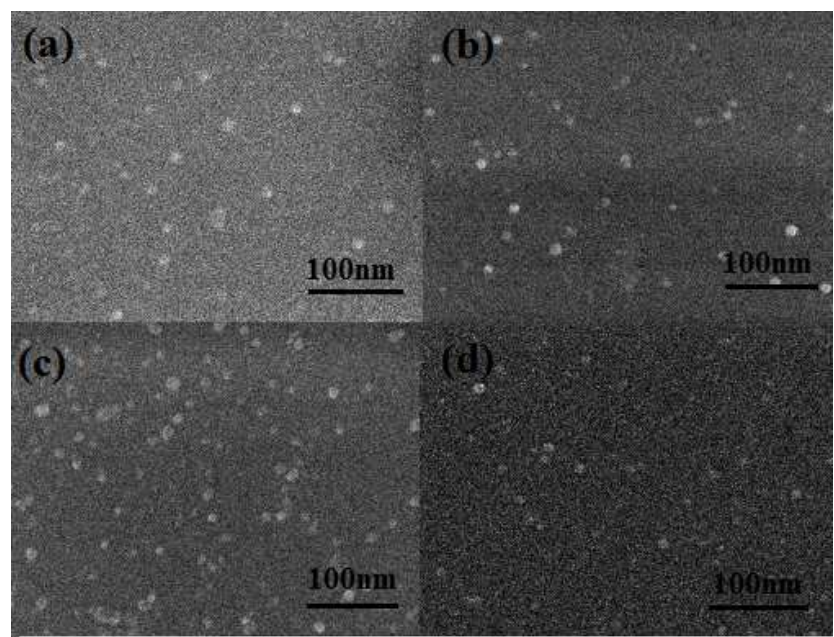

Fig.4. Fe-Sem image of $\mathrm{WO}_{3}$ film deposited at oxygen flow rate (a)30\%, (b)35\%, (c)40\%, and (d)50.

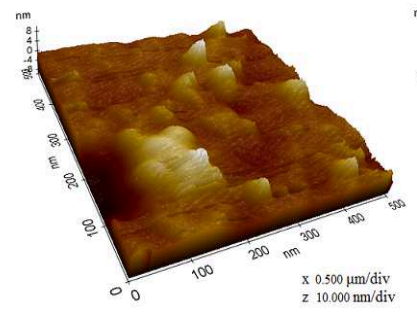

(a) $30 \%\left(\mathrm{Rq}_{\mathrm{q}}=2.056 \mathrm{~nm}\right)$

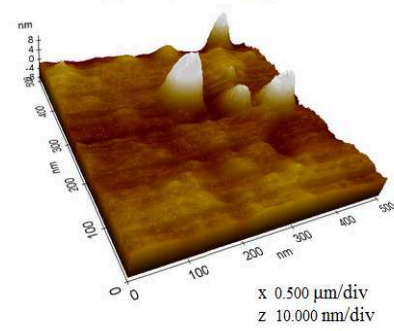

(C) $40 \%\left(\mathrm{R}_{\mathrm{q}}=2.644 \mathrm{~nm}\right)$

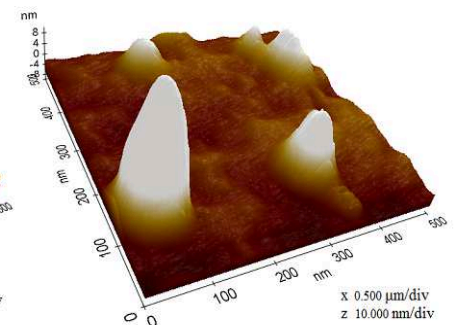

(b) $35 \%\left(\mathrm{Rq}_{\mathrm{q}}=5.261 \mathrm{~nm}\right)$

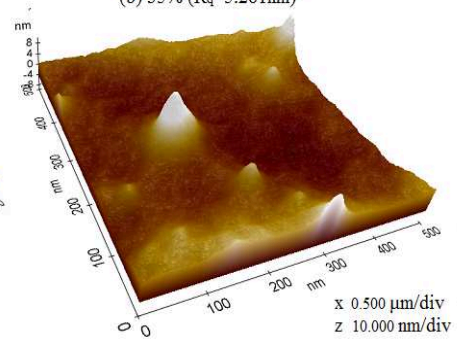

(d) $50 \%\left(\mathrm{R}_{\mathrm{q}}=2.747 \mathrm{~nm}\right)$

Fig.5. AFM image showing the roughness and surface morphology of $\mathrm{WO}_{3}$ films deposited at various oxygen flow.

Roughness $(\delta)$ of WO3 thin films were measure by using AFM, $\delta$ value of thin films from 2.026$5.261 \mathrm{~nm}$. Lowest $\delta$ is deposited at $30 \%$ oxygen and highest $\delta$ is deposited at $35 \%$ oxygen content. Result indicated that the surface is flat and dense, however miniature hump appeared in several areas. This result shows that variety of roughness is obvious by changing oxygen content in the fabrication process [7]. 


\section{B. Optical measurements}

Fig. 6 shows the transmittance spectra of the films at various oxygen flows. The transmittances of $550 \mathrm{~nm}$ at most film is about $83 \%$, the highest transmittance was detected at $30 \%$ oxygen flow about $86 \%$ in the visible spectra. From the result, the optical transmittance of WO3 films depends on the oxygen content during fabrication [8].

The transparency of films increased at lower oxygen content, this due to the low stoichiometric process during fabrication. At small oxygen content, the tungsten ion will have a small reaction to oxygen produces a small adhesion onto ITO substrate. Correspondingly, deposition rate of films decreased by increasing oxygen content.

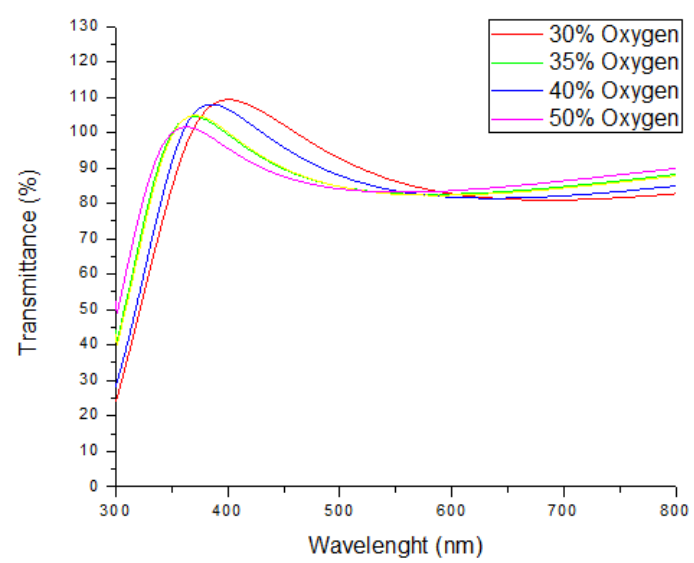

Fig.6. The optical transmittance spectra of the $\mathrm{WO}_{3}$ thin films deposited on ITO at various oxygen content.

\section{CONCLUSIONS}

Amorphous tungsten oxide WO3 thin films were deposited using RF magnetron sputtering by changing oxygen content. The electrical properties, optical properties and microstructure of the films have been studied. The films exhibit better electrochromic properties at $30 \%$ oxygen content. However the resistivity and crystallity of films need to be improving for future good. The enhanced electrochromism in these films is attributed to their high thickness about 140nm, small roughness, high crystallity, and have a good optical transmittance.

\section{ACKNOWLEDGMENT}

This present work was supported by MTUN COE vot no C023, Short Term Grant of Universiti Tun Hussein Onn Malaysia and Microelectronics \& Nanotechnology Shamsuddin Research Centre (MiNT-SRC).

\section{REFERENCES}

[1] A. Subrahmanyam, A. Karuppasamy, "Optical and electrochromic properties of oxygen sputtered tungsten oxide (WO3) thin films," Solar Energy Materials \& Solar Cells, Vol. 91, pp. 266-274, 2007.

[2] Xilian Sun, Zhimin Liu, Hongtao Cao, "Electrochromic properties of N-doped tungsten oxide thin films prepared by reactive DC-pulse sputtering" Thin Solid Films, PR China, Vol. 519, pp. 3032-3036, 2011.

[3] E. Washizu, A. Yamamoto, Y. Abe, M. Kawamura, K.Sasaki, "Optical and electrochromic properties of RF reactively sputtered WO3 films" Solid State Ionic, Hokaido Japan, Vol. 165, pp. 175-180, 2003. 
[4] Horng-hwa Lu, "Effect of oxygen content on the electrochromic properties of tungsten oxide films prepare by reactive magnetron sputtering" Journal of Alloy and Compound, Vol. 465, pp. 429-435, 2008.

[5] Cheng-Fu Yang, Chin-Guo Kuo, Ho Chang, Wen-Ray Chen, Ya-Chieh Tung, "Using Bi-Layer Stracture to Enhance the Electrochromic Properties of WO3: Self-Organized Nanotube Thin Films on DC Sputter Thin Films".

[6] I. Valyukh, S. Green, H. Arwin, G. A. Niklasson, E. Wäckelgård, C. G. Granqvist, "Spectroscopic ellipsometry characterization of electrochromic tungsten oxide and nickel oxide thin films made by sputter deposition” Solar Energy Material \& Solar Cells, Sweden, Vol. 94, pp. 724732, 2010.

[7] H. N. Cui and V. Teixeira, in Y. Zhou, Y. Gu and Z.Li (ed.) Mechanics and Material Engineering for Science and Experiments, Science Press New York Ltd, New York, 2001, p. 292295.

[8] Tien-syh Yang, Zhong-Ron Lin, Ming-Show Wong, "Structure and electrochromic properties of tungsten oxide films prepared by magnetron sputtering," Applied surface science, Vol. 252, pp. 2029-2037, 2005. 